\title{
PREEMPTIVE ANALGESIA
}

To every doctor, pain relief is not just a request or demand but is a basic human right of any patient who has pain. Pain is the commonest of all complaints made to doctors and its incidence far outscores all other complaints taken together. Belonging to the genre of medical practitioners which claims to expertise in pain and its relief, an anaesthetist must be equal to this challenge and actually relieve pain efficiently. But the hard reality is that we are not coping with this job well enough. This is evident from the fact that about $50 \%$ patients are not getting adequate relief from acute pain ${ }^{1}$. It is admissible that it is not only the anaesthetists who are to blame alone because in our community everybody tries to treat pain in his or her own way and there may be a lack of organization and application as well as understanding of the knowledge necessary for effective pain relief. There has been almost a total lack of efforts at practicing systematic analgesia by our anaesthetic colleagues.

Chronic pain has got its own set of aetiology and specific characteristics. It is difficult or sometimes impossible to fully control some of the cases of chronic pain syndromes. A systematic multidisciplinary approach in these cases can give better results and some comfort to the patient. Unfortunately, this humanitarian aspect of service is almost non-existent in our country. There is no denying the fact that organized multidisciplinary pain-clinic approach of systematic chronic pain relief is important. However, the importance of acquisition of a deeper insight and application of the state of the art of acute pain relief cannot be underestimated.

An evolving concept of control of long term ill effects of acute pain that is the focus of this discussion. Applying analgesic drugs indiscriminately is by no means the proper way to conquer the menace of acute pain. The answer lies in the approach, the strategy and application if a consistently effective acute pain relief service. The database gives us an idea of how older ideas in this context are being shunned or revamped and new ideas are being infused. A great deal of research and activities are going on round the world that we can enrich ourselves by. One such thing is the concept of preemptive analgesia ${ }^{2}$. This is not so new because two decades have past since the effect of prior anaesthesia was described on rats3. It was pointed out later that the mechanism involved was central sensitization to pain and preemptive analgesics can prevent it ${ }^{4}$.

The whole idea of preemptive analgesia arises from the fact that 'It is better to block pain before it arises'. This is not easy. Neither it is always pragmatic. In majority of cases, patients come with the complaint of already having the pain. But there are situations where pain has not yet started, but inevitably going to start sometime. Post surgical pain, labor pain, change of dressings etc are the instances of the predictable painful situations. It has already been mentioned that post surgical pain is the most appropriate arena for the application of preemptive analgesia because the onset of pain is precisely known. Although degree of pain may vary with type and extent of surgery, pain is, nevertheless, inevitable to follow. Potential for this acute pain becoming prolong with or without concomitant change in pain perception and pain behavior increases if pain is allowed to be felt by the patient for a reasonably long time after amputation of an extremity, the so-called phantom pain ${ }^{5}$, thoracotomy ${ }^{6}$, laparotomy ${ }^{7}$, herniorrhaphy ${ }^{8}$ and mastectomy ${ }^{9}$. Moreover, even low levels of residual pain are associated with decreased physical and social function as well as a diminished perception of overall health may be followed by long-term painful sequelae of surgery in both adults and children.

Research works conducted by different workers confirm the fact that preemptive analgesia works best when it is applied before the onset of phase 1 pain and when it is applied throughout the perioperative period ${ }^{2}$. This reiterates what is already known, patients must be protected from pain in the perioperative period. We now know why.

One questiong' remains to be answered. What are the drugs and techniques available to deploy preemptive analgesia? Before answering this, we must confess that we really do not know for sure. Certain observations tend to reveal that ability to block both central and peripheral sensitization phenomenon may not be equal in all analgesics. Morphine is a beneficial drug in this respect because it has been shown that if used before applying painful stimuli and reversed with naloxone before the expected onset of phase 2 pain, sensitization is either prevented or reduced. Whereas intraoperative administration of 
isoflurane does not do so ${ }^{10}$. This also tells us that the so called process of central pain sensitization can occur even in unconscious state where there is no apparent response to ongoing painful surgical stimuli. Other analgesic like fentanyl and ketamine $^{\text {ll }}$, anti-inflammatory agents ${ }^{12}$ and neural blockade ${ }^{13}$ may likewise vary in their ability to block sensitization and when the complete picture comes out in future, we can evaluate them according to their preemptive value which we cannot do today.

Not only the drugs but also different techniques are being reevaluated according to their preemptive efficacy. For example, epidural anaesthesia covering the whole of postoperative period is one of the best techniques 14 probably because it fulfils all the requirements of preemptive analgesia i.e. early application, applied throughout postoperative period and conduction block. If this is true then epidural catheters may be recommended to be introduced in all relevant cases even if the primary general anaesthesia is being employed. There is already a growing awareness of the fact that Infiltration with local analgesic solution before incision gives better result in long term pain prevention as compared to it applied at the end of suturing ${ }^{14}$.

It should be clear that there may be something valuable in the offing for us to go on with increased enthusiasm as farkcute pain relief is concerned. Although there are a number of articles published on a pessimistic note about the efficacy of preemptive analgesia, reasons for apparent failure to show efficacy in those works have also been put forward. Let us believe, for the sake of our poor patients reeling helplessly with postoperative or other types of acute pain, that we have found a tool to combat it decisively. Optimistic research works ought to be undertaken by our anaesthetic colleagues and join forces with those who are out to show that it does work. Acute pain can indeed be conquered with the new tool called preemptive analgesia.

\section{REFERENCES}

1. Siwek J. Twelve pitfalls of adequate pain control [Editorial]. Am Fam Physician 1997;56:726-32.

2. Gottschalk A, Smith DS. New concepts in acute pain therapy: preemptive analgesia. Am Fam Physician 2001;63:1979-84,1985-6.

3. Gonzalez-Darder JM, Barbera J, Abellan MJ. Effects of prior anaesthesia on autotomy following sciatic transection in rats. Pain
1986;24:87-91.

4. Woolf CJ, Chong MS. Preemptive analgesia treating postoperative pain by preventing the establishment of central sensitization. Anesth Analg 1993;77:362-79.

5. Sherman RA, Devor M, Heermann-Do K. Phantom pain. New York: Plenum, 1997.

6. Dajczman E, Gordon A, Kreisman H, Wolkove N. Long-term postthoracotomy pain. Chest 1991;99: 270-4.

7. Gottschalk A, Smith DS, Jobes DR, Kennedy SK, Lally SE, Noble VE, et al. Preemptive epidural analgesia and recovery from radical prostatectomy: a randomized controlled trial. JAMA 1998;279:1076-82.

8. Callesen T, Kehlet H. Postherniorrhaphy pain. Anesthesiology 1997;87:1219-30.

9. De Vries JE, Timmer PR, Erftemeier EJ, van der Weele LT. Breast pain after breast conserving therapy. Breast 1994;3:151-4.

10. Tverskoy M, Oz Y, Isakson A, Finger J, Bradley EL, Kissin I. Preemptive effect of fentanyl and ketamine on postoperative pain and wound hyperalgesia. Anesth Analg 1994;78:205-9.

11. Souter AJ, Fredman B, White PF. Controversies in the perioperative use of nonsteroidal antiinflammatory drugs. Anesth Analg 1994;79:1178-90.

12. Cousins MJ, Veering BT. Epidural neural blockade. In: Cousins MJ, Bridenbaugh PO, eds. Neural blockade in clinical anesthesia and management of pain. $3 \mathrm{~d}$ ed. Philadelphia: Lippincott-Raven, 1998:243-321.

13. Bach S, Noreng MF, Tjellden NU. Phantom limb pain in amputees during the first 12 months following limb amputation after preoperative lumbar epidural blockage. Pain 1988;33:297-301.

14. Tverskoy M, Cozacov C, Ayache M, Bradley EL, Kissin I. Postoperative pain after inguinal herniorrhaphy with different types of anesthesia. Anesth Analg 1990;70:29-3

\section{A.Y.F. Elahi Chowdhury}

Professor, Department of Anaesthesiology, National Institute of Cardiovascular Diseases, Sher-e-Bangla Nagar, Dhaka. 